\title{
How far the substituent effects in disubstituted cyclohexa-1,3-diene derivatives differ from those in bicyclo[2.2.2]octane and benzene?
}

\author{
Halina Szatylowicz ${ }^{1}$ (D) - Anna Jezuita ${ }^{2} \cdot$ Tomasz Siodla $^{3} \cdot$ Konstantin S. Varaksin $^{4} \cdot$ Krzysztof Ejsmont $^{2}$. \\ Mozhgan Shahamirian ${ }^{5} \cdot$ Tadeusz M. Krygowski $^{6}$
}

Received: 9 February 2018 / Accepted: 19 April 2018 / Published online: 9 June 2018

(C) The Author(s) 2018

\begin{abstract}
Substituents effects in cyclic diene derivatives are studied using quantum chemical modeling and compared to the corresponding effects in aromatic (benzene) and fully saturated (bicyclo[2.2.2]octane) compounds. In particular, electronic properties of the fixed group $\mathrm{Y}$ in a series of 3- and 4-X-substituted cyclohexa-1,3-diene-Y derivatives (where $\mathrm{Y}=\mathrm{NO}_{2}, \mathrm{COOH}, \mathrm{COO}^{-} \mathrm{OH}, \mathrm{O}^{-}$, $\mathrm{NH}_{2}$, and $\mathrm{X}=\mathrm{NMe}_{2}, \mathrm{NH}_{2}, \mathrm{OH}, \mathrm{OMe}, \mathrm{Me}, \mathrm{H}, \mathrm{F}, \mathrm{Cl}, \mathrm{CF}_{3}, \mathrm{CN}, \mathrm{CHO}, \mathrm{COMe}, \mathrm{CONH}_{2}, \mathrm{COOH}, \mathrm{NO}_{2}, \mathrm{NO}$ ) are examined using the B3LYP/6-311++G(d,p) method. For this purpose, quantum chemistry models of the substituent effect: cSAR (charge of the substituent active region) and SESE (substituent effect stabilization energy) as well as traditional Hammett's substituent constants $(\sigma)$ and their inductive $(F)$ and resonance $(R)$ components are used. $\pi$-electron delocalization of the transmitting moiety (butadiene fragment of the CHD) is described by the HOMA index. This comparative study reveals interplay between inductive and resonance contributions to the substituent effect.
\end{abstract}

Keywords Substituent effects $\cdot$ Electronic structure $\cdot$ Molecular modeling $\cdot$ Substituent effect stabilization energy $\cdot$ Charge of the substituent active region

In memory of professor Roman E. Sioda (1937-2018).

Electronic supplementary material The online version of this article (https://doi.org/10.1007/s11224-018-1113-5) contains supplementary material, which is available to authorized users.

Halina Szatylowicz

halina@ch.pw.edu.pl

Anna Jezuita

ajezuita@uni.opole.pl

1 Faculty of Chemistry, Warsaw University of Technology, Noakowskiego 3, 00-664 Warsaw, Poland

2 Faculty of Chemistry, Opole University, Oleska 48, 45-052 Opole, Poland

3 Faculty of Chemistry, Adam Mickiewicz University, Umultowska 89b, 61-614 Poznań, Poland

4 Department Organic Chemistry, Omsk F.M. Dostoevsky State University, Mira 55A, 644077 Omsk, Russia

5 Department of Chemistry, Faculty of Science, Sarvestan Branch, Islamic Azad University, Sarvestan, Iran

6 Department of Chemistry, Warsaw University, Pasteura 1, 02-093 Warsaw, Poland

\section{Introduction}

Cyclohexa-1,3-diene (CHD) derivatives substituted in positions 3 and 4, with substituents differing in their electronattracting/electron-donating properties, allow to visualize how far the substituent effects in mixed paraffin/diene alicyclic system differ from the pure $\mathrm{sp}^{3}$ bicyclo[2.2.2] octane (BCO) and pure aromatic benzene (BEN). Cyclic compounds combining $\mathrm{sp}^{2}$ and $\mathrm{sp}^{3}$ carbons in one molecule are relatively frequent and play an important role in technology [1-5]. The reference systems are well recognized. The pi-electron system in benzene is known as being resistant to deformation due to the substituent effects [6], the property which is also known to be responsible for substantially lower reactivity of benzene in comparison to the alkene-type systems [7, 8]. Logically, cyclic fully $\mathrm{sp}^{3}$ hybridized system is taken as the second reference.

The substituent effects in benzene derivatives are usually differentiated into those acting in meta and in para substituted species [9]. It is assumed that the substituent effects in these two positions differ by means of mechanism of transmission: in the para position, there is a similar contribution of resonance and inductive (field) effects, whereas in meta position, the contribution of resonance effect is substantially lower 


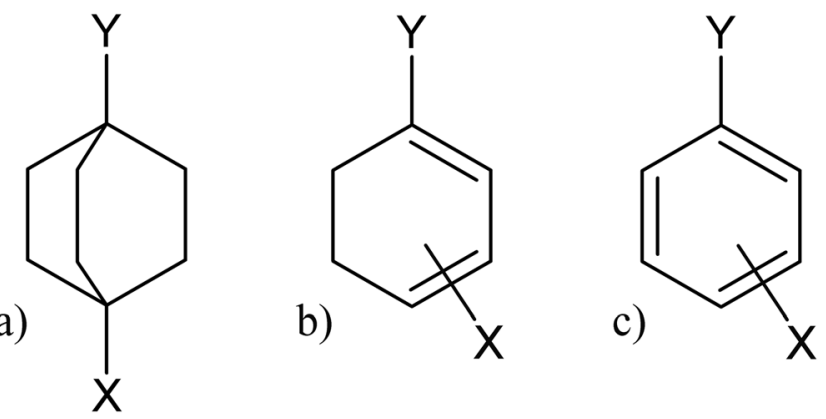

Scheme 1 Studied substituted X-R-Y systems: BCO (a), CHD (b), and $\mathrm{BEN}(\mathbf{c})$ derivatives; $\mathrm{Y}=\mathrm{NO}_{2}, \mathrm{COOH}, \mathrm{COO}^{-} \mathrm{OH}, \mathrm{O}^{-}$, and $\mathrm{NH}_{2}$ and $\mathrm{X}=$ $\mathrm{NMe}_{2}, \mathrm{NH}_{2}, \mathrm{OH}, \mathrm{OMe}, \mathrm{Me}, \mathrm{H}, \mathrm{F}, \mathrm{Cl}, \mathrm{CF}_{3}, \mathrm{CN}, \mathrm{CHO}, \mathrm{COMe}, \mathrm{CONH}_{2}$, $\mathrm{COOH}, \mathrm{NO}_{2}$, and $\mathrm{NO}$

[10-12]. A very important feature of the Hammett approach to the substituent effect is not only the description of its magnitude for a particular substituent $\mathrm{X}$ by substituent constants $\sigma(\mathrm{X})$, but also showing a sensitivity of a given chemical reaction or physicochemical property $\mathrm{P}(\mathrm{X})$ on the substituent effect. This is described by means of the Hammett equation (1) by the reaction constant $\varrho$.

$\mathrm{P}(\mathrm{X})=\mathrm{\rho} \sigma(\mathrm{X})$

The reaction constants depend strongly on a few factors [12]: firstly, on the kind of the reaction or physicochemical properties taken into consideration; secondly, on the thermodynamic conditions of the process (pressure, temperature, concentration, solvent, or other environment of the process); and thirdly, the nature of a molecular system in which the process is carried out. A good example is $\varrho$ value for ionization of benzoic acids; in water, it is by definition 1.00 but in 1:1 water:ethanol solution, it is 1.52 [13] and in the gas phase, $\varrho=5.6$ [14]. For other molecular systems, e.g., phenols $\varrho$ is 2.23 in water [15] (for wider review, see Krygowski and Fawcett [16]). The Hammett reaction constants depend on units of the properties for systems and properties taken into account. Recent studies allowed to show that application of the charge of the substituent active region (cSAR) concept $[17,18]$ to various molecular systems with any substituents and "reaction sites" as well as a transmitting moiety $\mathrm{R}$ in X-R-Y systems can be described by regression $\operatorname{cSAR}(Y)$ on $\operatorname{cSAR}(\mathrm{X})$ with a result in the same scale of magnitude. The substituted $\mathrm{CHD}$ and for comparison $\mathrm{BCO}$ and benzene derivatives are subject of this studies.

In the case of $\mathrm{BCO}$, the substituent effect is due to inductive effect operating through the bonds [19-21] or to the field effect, acting via space [22, 23] (for general review, see Exner and Böhm [24]).

The aim of this study is to examine the substituent effect in disubstituted cyclohexa-1,3-diene (CHD) systems as well as to evaluate the relationships between an impact of the substituents realized in those series with those found in bicyclo[2.2.2] octane (BCO) [25] and benzene (BEN) [26-29] systems. All considered X-R-Y derivatives are shown in Scheme 1. The results of our recent study show the usefulness of substituent effect stabilization energy (SESE) and cSAR concepts to describe substituent effects (also by inductive and resonance contributions) in 4-X-BCO-1-Y and 4-XBEN-1-Y derivatives [25]. As already mentioned, the CHD ring consists of two parts: saturated and unsaturated, through which the effect is transmitted parallelly by $\mathrm{sp}^{2}$ and $\mathrm{sp}^{3}$ carbons. Thus, the comparison of the substituent effect observed in alicyclic BCO and aromatic BEN with the one in CHD derivatives may reveal an interplay between inductive and resonance contributions to the substituent effect.

\section{Methodology}

To investigate substituent effects in mixed paraffinic and olefinic alicyclic systems, series of 4-X-CHD-1-Y and 3-X-CHD-1-Y derivatives with six fixed groups $\left(\mathrm{Y}=\mathrm{NO}_{2}, \mathrm{COOH}, \mathrm{COO}^{-}\right.$, $\mathrm{OH}, \mathrm{O}^{-}, \mathrm{NH}_{2}$ ) and the 16 substituents $(\mathrm{X})$ (see Scheme 1b) were
Fig. 1 Dependences of HOMA on SESE for 4-X-CHD-NO ${ }_{2}$ and 4-X-CHD-OH series

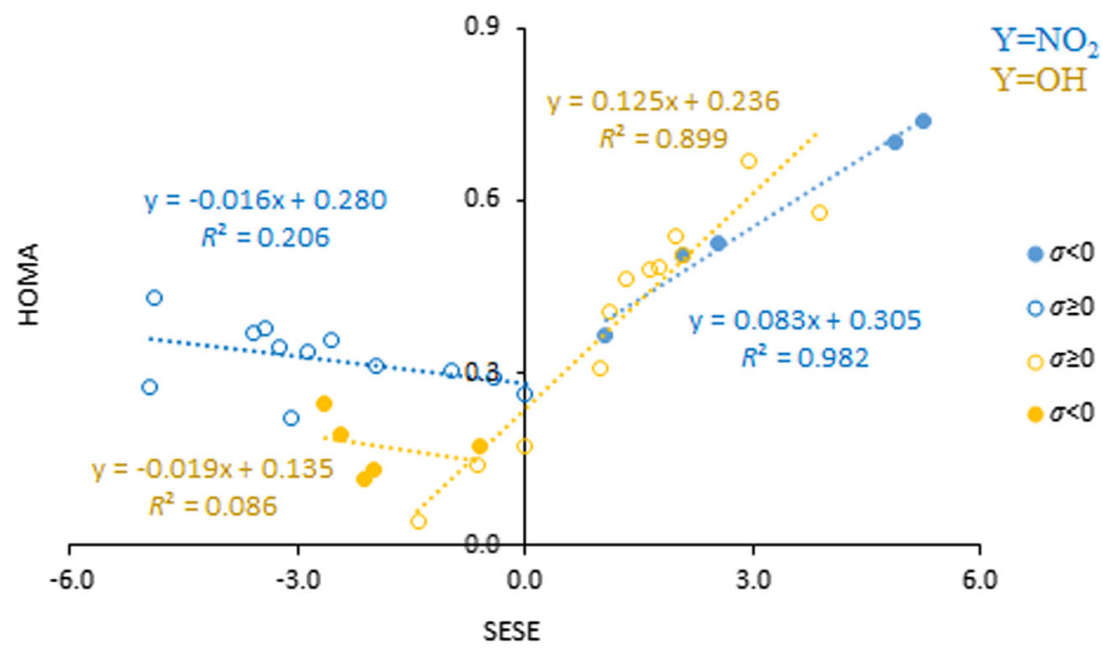


Table 1 Values of the slope, $a$, and determination coefficient, $R^{2}$, for the obtained linear relations between substituent effect parameters for 1-4 and 1-3 substituted CHD-Y series

\begin{tabular}{|c|c|c|c|c|c|c|}
\hline \multirow[t]{2}{*}{ Y } & \multicolumn{2}{|c|}{$\mathrm{SESE}_{1-3}$ vs $\mathrm{SESE}_{1-4}$} & \multicolumn{2}{|c|}{$\operatorname{cSAR}(\mathrm{X})_{1-3} \operatorname{vs} \operatorname{cSAR}(\mathrm{X})_{1-4}$} & \multicolumn{2}{|c|}{$\operatorname{cSAR}(\mathrm{Y})_{1-3}$ vs cSAR $(\mathrm{Y})_{1-4}$} \\
\hline & $R^{2}$ & $a$ & $R^{2}$ & $a$ & $R^{2}$ & $a$ \\
\hline $\mathrm{NO}_{2}$ & 0.698 & $0.370 \pm 0.063$ & 0.974 & $0.678 \pm 0.029$ & 0.585 & $0.219 \pm 0.048$ \\
\hline $\mathrm{COOH}$ & 0.479 & $0.208 \pm 0.058$ & 0.977 & $0.711 \pm 0.029$ & 0.549 & $0.222 \pm 0.054$ \\
\hline $\mathrm{COO}^{-}$ & 0.690 & $0.438 \pm 0.079$ & 0.962 & $0.676 \pm 0.036$ & 0.476 & $0.182 \pm 0.051$ \\
\hline $\mathrm{OH}$ & 0.591 & $0.127 \pm 0.027$ & 0.986 & $0.745 \pm 0.023$ & 0.396 & $0.175 \pm 0.056$ \\
\hline $\mathrm{O}^{-}$ & 0.748 & $0.293 \pm 0.044$ & 0.947 & $0.551 \pm 0.034$ & 0.587 & $0.197 \pm 0.043$ \\
\hline $\mathrm{NH}_{2}$ & 0.590 & $0.136 \pm 0.030$ & 0.968 & $0.680 \pm 0.033$ & 0.428 & $0.167 \pm 0.052$ \\
\hline
\end{tabular}

used. For each studied system, an optimization without any symmetry constraints was performed using the Gaussian09 program [30]. Based on the results of previous studies [26], the B3LYP/6$311++G(d, p)$ method was used for all calculations. The vibrational frequencies were calculated at the same level of theory to confirm that all obtained structures correspond to the minima on the potential energy surface. In the case of amino series, previously obtained structures [31] were used.

The substituent properties were described by SESE and cSAR parameters. SESE descriptors were obtained as the homodesmotic reaction energy (Eq. 2) [32]:

$$
\begin{aligned}
\mathrm{SESE}=E\left(\mathrm{CHD}^{-1}(2) \mathrm{X}\right)+E(\mathrm{CHD}-1-\mathrm{Y}) \\
-E(4(3)-\mathrm{X}-\mathrm{CHD}-1-\mathrm{Y})-E(\mathrm{CHD})
\end{aligned}
$$

The cSAR descriptor was calculated as a sum of charges at all atoms of the substituent $\mathrm{X}$ or $\mathrm{Y}$ and the charge at the ipso carbon atom $[17,18]$; cSAR values for carbon atoms in positions 2, 3, 5, and 6 of the CHD ring were obtained by summing up the atomic charges of carbon and hydrogens. Following the earlier studies [25, 27], the Hirshfeld method was applied to calculate all cSAR values [33]. It should be added that this method for fragments characterized by substantial cSAR variability leads to similar results as NBO charge assessments [27, 34].
The effect of substituent on $\pi$-electron delocalization of a transmitting moiety was characterized by a geometry-based aromaticity index HOMA (harmonic oscillator model of aromaticity) [35]. HOMA is defined as a normalized sum of squared deviations of bond lengths from the values for a system assumed to be fully aromatic. The appropriate expression is given by Eq. (3).

$\mathrm{HOMA}=1-\frac{1}{n} \sum_{i=1}^{n} \alpha\left(d_{o p t}-d_{i}\right)^{2}$

where $n$ is the number of CC bonds taken into consideration, $\alpha=257.7$ is an empirical normalization constant chosen to give $\mathrm{HOMA}=0$ for non-aromatic system and $\mathrm{HOMA}=1$ for a system where all bonds are equal to $d_{\text {opt }}=1.388 \AA$, and $d_{\mathrm{i}}$ is the bond length. In the case of CHD derivatives, changes of $\pi$-electron delocalization were obtained for the butadiene unit/fragment of the molecule.

\section{Results and discussion}

Molecules of CHD consist of two subunits which dramatically differ from the viewpoint of their electronic structure. In particular, in the CHD ring, a saturated part with carbon atoms in
Fig. 2 Dependences of cSAR(X) values in 1-4 and 1-3 substituted CHD-Y derivatives, where $\mathrm{Y}=$ $\mathrm{NO}_{2}, \mathrm{COOH}, \mathrm{COO}^{-}, \mathrm{OH}, \mathrm{O}^{-}$, and $\mathrm{NH}_{2}$

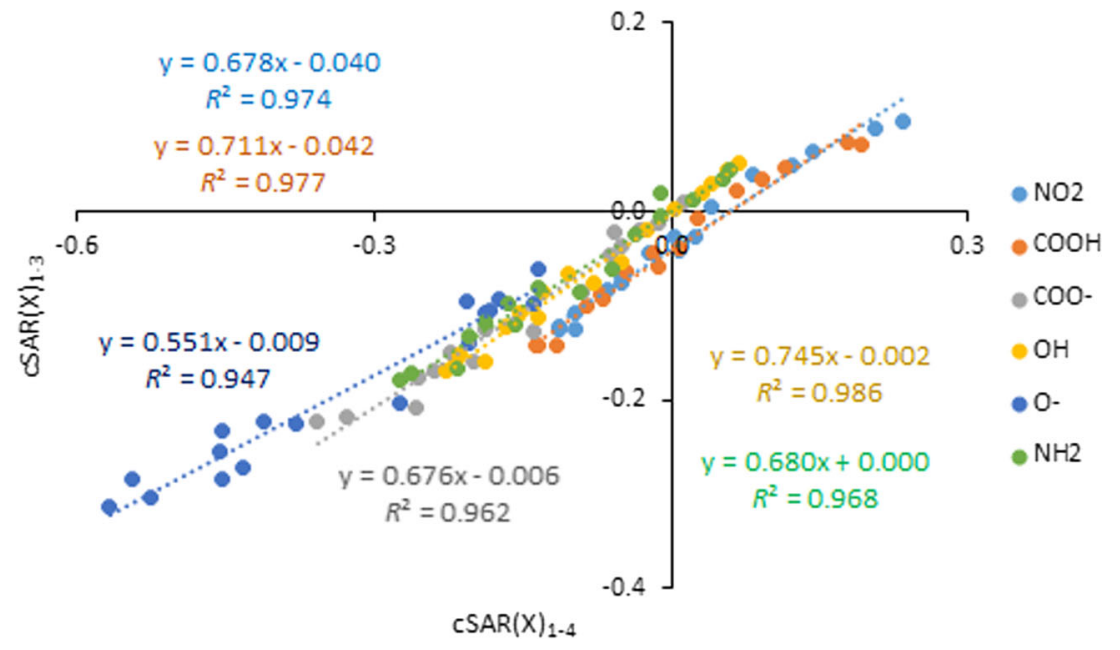


Table 2 The maximum and minimum values as well as variability range of the $\operatorname{cSAR}(\mathrm{Y})$ and $\operatorname{cSAR}(\mathrm{X})$ for 1-4 and 1-3 substituted CHD$\mathrm{Y}$ series

\begin{tabular}{|c|c|c|c|c|c|c|}
\hline \multirow[t]{2}{*}{ Y } & \multicolumn{3}{|c|}{$\operatorname{cSAR}(Y)$} & \multicolumn{3}{|c|}{$\operatorname{cSAR}(\mathrm{X})$} \\
\hline & Max & Min & Range & Max & Min & Range \\
\hline \multicolumn{7}{|l|}{$1-4$} \\
\hline $\mathrm{NO}_{2}$ & -0.108 & -0.271 & 0.164 & 0.233 & -0.113 & 0.346 \\
\hline $\mathrm{COOH}$ & -0.043 & -0.194 & 0.150 & 0.192 & -0.136 & 0.328 \\
\hline $\mathrm{COO}^{-}$ & -0.659 & -0.827 & 0.168 & 0.013 & -0.357 & 0.370 \\
\hline $\mathrm{OH}$ & 0.131 & 0.021 & 0.110 & 0.067 & -0.226 & 0.294 \\
\hline $\mathrm{O}^{-}$ & -0.273 & -0.429 & 0.156 & -0.135 & -0.567 & 0.432 \\
\hline $\mathrm{NH}_{2}$ & 0.222 & 0.053 & 0.169 & 0.060 & -0.274 & 0.334 \\
\hline \multicolumn{7}{|l|}{$1-3$} \\
\hline $\mathrm{NO}_{2}$ & -0.128 & -0.173 & 0.045 & 0.095 & -0.125 & 0.220 \\
\hline $\mathrm{COOH}$ & -0.068 & -0.112 & 0.044 & 0.074 & -0.143 & 0.217 \\
\hline $\mathrm{COO}^{-}$ & -0.749 & -0.792 & 0.043 & 0.011 & -0.224 & 0.234 \\
\hline $\mathrm{OH}$ & 0.089 & 0.056 & 0.032 & 0.052 & -0.169 & 0.221 \\
\hline $\mathrm{O}^{-}$ & -0.362 & -0.402 & 0.040 & -0.062 & -0.314 & 0.253 \\
\hline $\mathrm{NH}_{2}$ & 0.146 & 0.102 & 0.044 & 0.044 & -0.179 & 0.223 \\
\hline
\end{tabular}

$\mathrm{sp}^{3}$ hybridization state can be distinguished, coexisting with an unsaturated one built up of $\mathrm{sp}^{2}$ hybridized carbons. Hence, the substituent effects in CHD represent a significant complexity due to different transmission pathways via mutually interacting unsaturated and saturated parts of the molecule. For this reason, the obtained results are presented in three subsections devoted to (i) substituent effects in 3- or 4-Xsubstituted CHD-1-Y derivatives, then (ii) a comparison with 4-X-BCO-1-Y substituted systems and finally, (iii) a comparison with disubstituted benzene derivatives.

Additionally, to facilitate the presentation of the results and discussion on the substituent effect in 4-X-R-1-Y $(\mathrm{R}=\mathrm{BCO}$, $\mathrm{CHD}$, and $\mathrm{BEN})$ and $3-\mathrm{X}-\mathrm{R}-1-\mathrm{Y}(\mathrm{R}=\mathrm{CHD}$ and $\mathrm{BEN})$, particular series are denoted as 1-4 and 1-3 (para and meta) derivatives, respectively. Principal substituent effect characteristics of the studied compounds are collected in

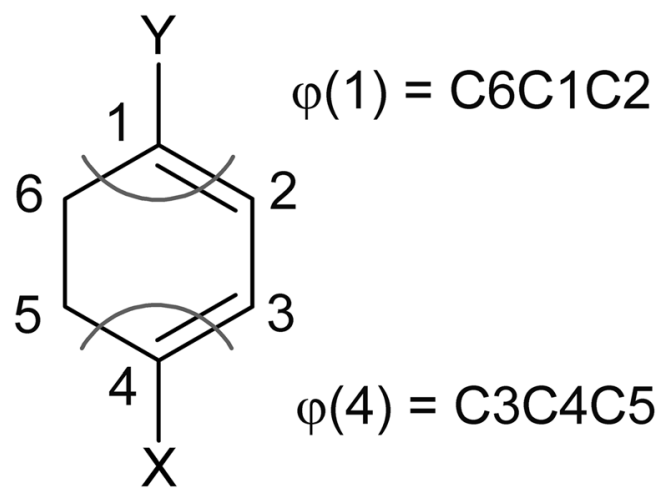

Scheme 2 Labeling of atoms and angles in 4-X-CHD-Y derivatives
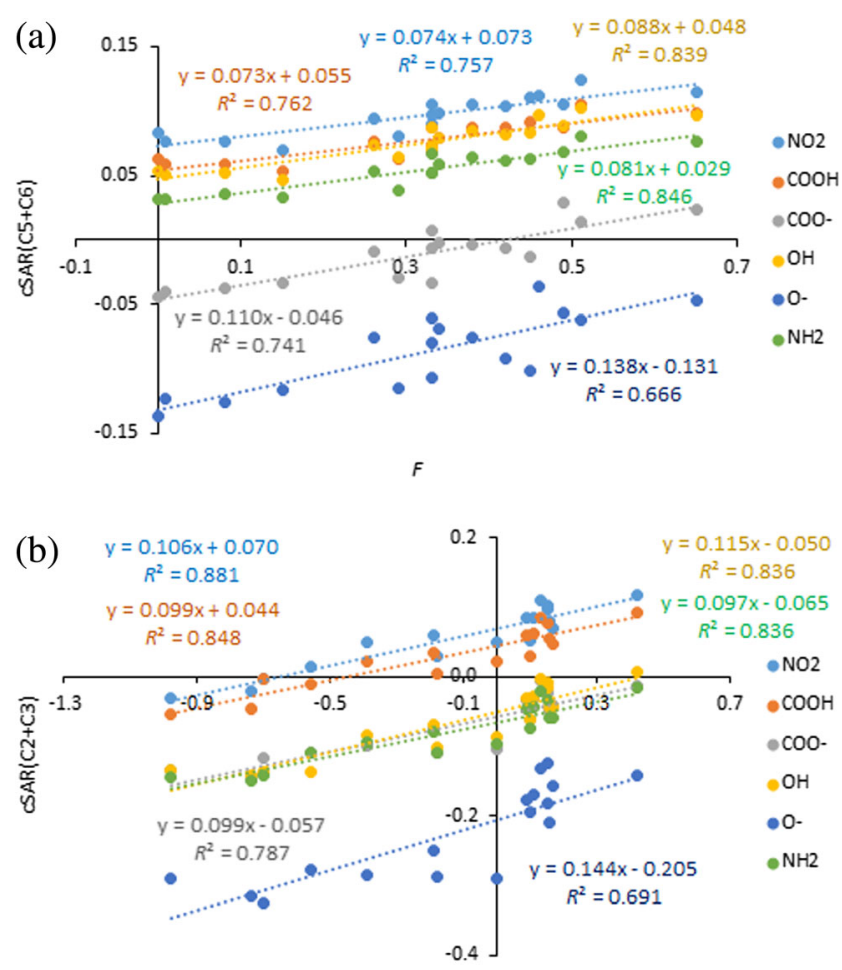

Fig. 3 The relationships between sum of $\operatorname{cSAR}(\mathrm{C} 5)$ and cSAR(C6), cSAR $(\mathrm{C} 5+\mathrm{C} 6)$, and $F(\mathbf{a})$ and sum of $\operatorname{cSAR}(\mathrm{C} 2)$ and $\mathrm{cSAR}(\mathrm{C} 3)$, $\mathrm{cSAR}(\mathrm{C} 2+\mathrm{C} 3)$, and $R$ (b) for 1-4 substituted derivatives of CHD-Y, where $\mathrm{Y}=\mathrm{NO}_{2}, \mathrm{COOH}, \mathrm{COO}^{-}, \mathrm{OH}, \mathrm{O}^{-}$, and $\mathrm{NH}_{2}$

Tables S1-S10 of the Supplementary Information whereas statistics of the discussed interrelations between substituent effect descriptors for the studied derivatives are shown in Tables S11-S15.

\section{Substituent effects in 1-4 and 1-3 disubstituted CHD derivatives}

At the beginning, it should be emphasized that the obtained results of the used quantum chemistry-based substituent effect

Table 3 Values of the slope, $a$, and determination coefficient, $R^{2}$, for the obtained linear relations: (i) sum of $\operatorname{cSAR}(\mathrm{C} 6)$ and $\operatorname{cSAR}(\mathrm{C} 5)$ with inductive constant $(F)$ and (ii) sum of $\operatorname{cSAR}(\mathrm{C} 2)$ and $\operatorname{cSAR}(\mathrm{C} 3)$ with resonance constant $(R)$ in 1-4 CHD-Y series

\begin{tabular}{llllll}
\hline $\mathrm{Y}$ & \multicolumn{2}{c}{$\mathrm{cSAR}(\mathrm{C} 5+\mathrm{C} 6) \mathrm{vs} F$} & & \multicolumn{2}{c}{$\mathrm{cSAR}(\mathrm{C} 2+\mathrm{C} 3) \mathrm{vs} R$} \\
\cline { 2 - 3 } \cline { 6 - 7 } & $R^{2}$ & $a$ & & $R^{2}$ & $a$ \\
\hline $\mathrm{NO}_{2}$ & 0.788 & $0.074 \pm 0.010$ & & 0.882 & $0.109 \pm 0.010$ \\
$\mathrm{COOH}$ & 0.762 & $0.073 \pm 0.011$ & & 0.848 & $0.099 \pm 0.011$ \\
$\mathrm{COO}^{-}$ & 0.741 & $0.110 \pm 0.017$ & & 0.787 & $0.099 \pm 0.014$ \\
$\mathrm{OH}$ & 0.839 & $0.088 \pm 0.010$ & & 0.836 & $0.115 \pm 0.013$ \\
$\mathrm{O}^{-}$ & 0.666 & $0.138 \pm 0.025$ & & 0.691 & $0.144 \pm 0.025$ \\
$\mathrm{NH}_{2}$ & 0.846 & $0.081 \pm 0.009$ & 0.836 & $0.097 \pm 0.012$ \\
\hline & & & &
\end{tabular}


Fig. 4 Dependence of valence angle $\varphi(1)$ and $\varphi(4)$ in disubstituted 4-X-CHD- $\mathrm{NO}_{2}$ on the $\varphi(4)$ angle in $4-\mathrm{X}-\mathrm{CHD}-1-\mathrm{H}$ (monosubstituted) systems

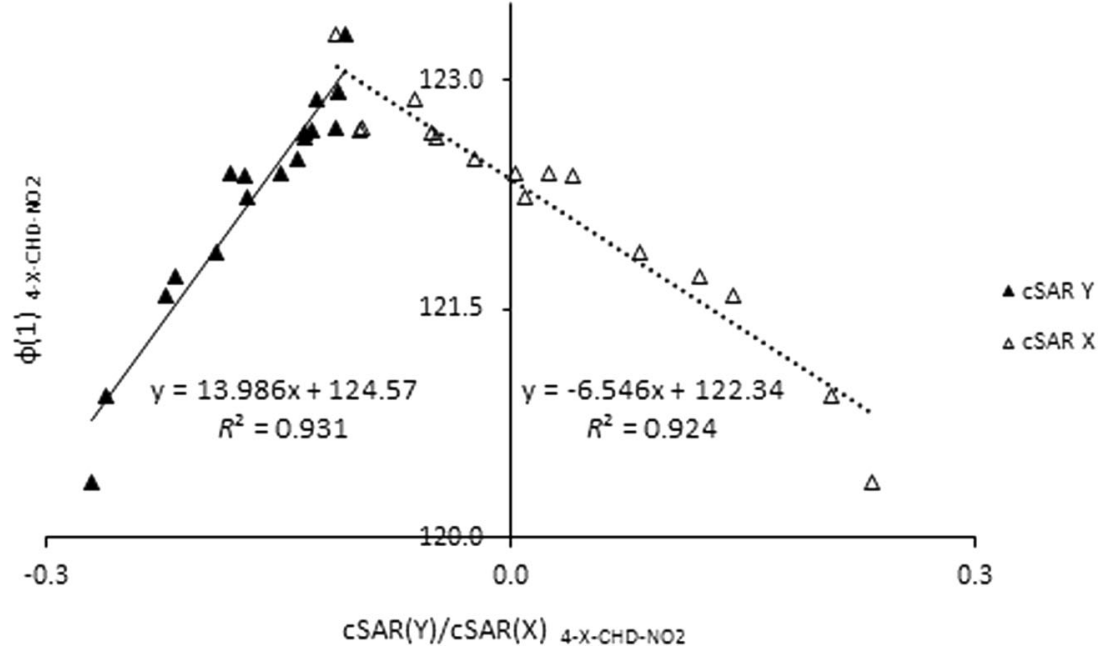

characteristics (cSAR and SESE) are correlated both mutually as well as with the appropriate Hammett $\sigma$ constants [36] (see Table S11 in Supplementary Information). Alike in the case of substituted CHD-amine derivatives [31], much better correlations are found for the 1-4 series than the 1-3 ones. The same can be stated taking into account Hammett-like relations, i.e., cSAR(Y) vs SESE, $\operatorname{cSAR}(\mathrm{Y})$ vs $\operatorname{cSAR}(\mathrm{X})$, or $\operatorname{cSAR}(\mathrm{Y})$ vs $\sigma$ (Table S12). For 1-3 substituted hydroxy derivatives, the worst description of interdependencies (low $R^{2}$ ) both between substituent effect characteristics and for classical model of the substituent effect should be noted. Additionally, in most cases, the absolute values of the slopes are also the smallest. It may be interpreted in terms of unusual properties of meta position in phenol [27], the Hammett substituent constant is in this case 0.12 [36], indicating the electron-attracting property of this position.

It has recently been found that the $\pi$-electron delocalization in the butadiene unit of monosubstituted CHD depends on the properties of the substituent [37]. An application of the HOMA index reveals that electron-accepting or electrondonating groups increase its $\pi$-electron delocalization. The same can be stated in the case of disubstituted 1-4 CHD derivatives. Moreover, very good correlations between HOMA and SESE are observed for systems with an opposite character of the substituent $\mathrm{X}$ and the fixed group $\mathrm{Y}$ (for the neutral $\mathrm{Y}$ ), whereas significantly worse or no correlations are found in the case of derivatives with the same electronic properties of $\mathrm{X}$ and Y (see Table S13). In the first case, the increase of substituent stabilization effect (SESE $>0$ ) is associated with an increase of $\pi$-electron delocalization (Fig. 1). No clear picture is found for 1-3 CHD systems (Table S13).

Undoubtedly, it is interesting to compare the dependence of the substituent effect on position of the substituent. When the substituent effect characteristics [SESE, cSAR(X), and cSAR(Y)] for 1-3 disubstituted CHD are regressed against those subtituted in 1-4 positions, only correlations for cSAR(X) have high $R^{2}$ value (the worst value is 0.947 , excluding charged substituents 0.968 ) (see Table 1 ). In all cases, the slopes are less than 1: for uncharged substituents, they are in the range between 0.678 and 0.745 whereas for $\mathrm{COO}^{-}$and $\mathrm{O}^{-}$, the values are 0.676 and 0.551 , respectively (Fig. 2). These results document a much worse cooperation between
Fig. 5 Relationships between cSAR(X) values in 4-X-CHD-Y and in CHD-X systems

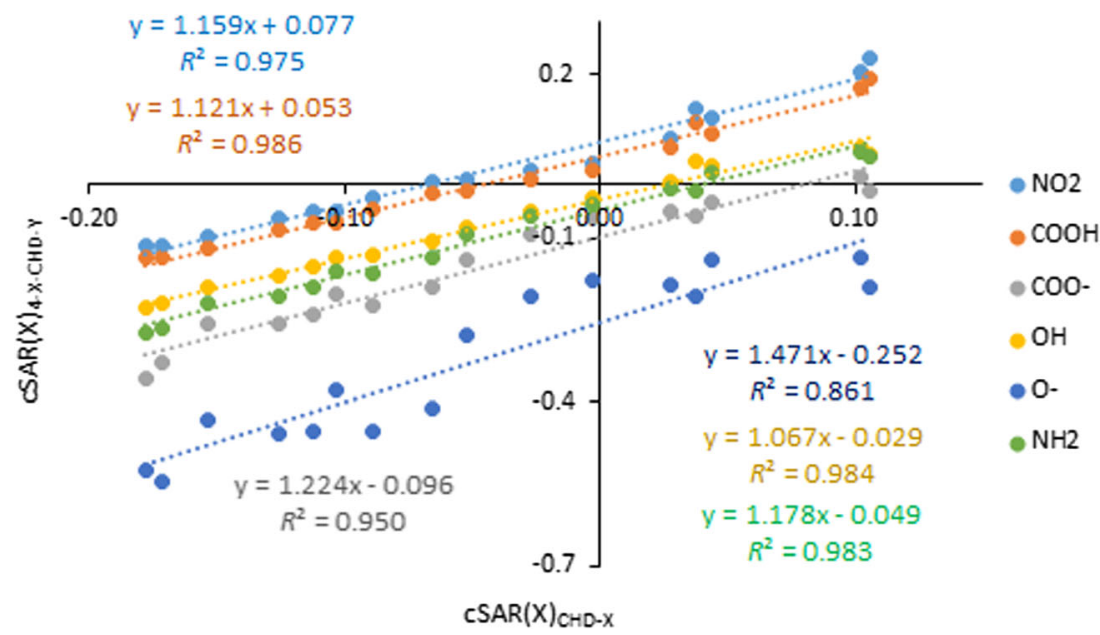


Table 4 Values of the slope, $a$, and determination coefficient, $R^{2}$, for the obtained linear relations between $\operatorname{cSAR}(\mathrm{X})$ values in $4-\mathrm{X}-\mathrm{CHD}-\mathrm{Y}$, in cSAR $(\mathrm{X})_{4-\mathrm{X}-\mathrm{CHD}-\mathrm{Y}}$, and in CHD-X, cSAR(X) $)_{\mathrm{CHD}-\mathrm{X}}$ systems

\begin{tabular}{lll}
\hline $\mathrm{Y}$ & \multicolumn{2}{c}{$\mathrm{cSAR}(\mathrm{X})_{4-\mathrm{X}-\mathrm{CHD}-\mathrm{Y}} \mathrm{vs} \operatorname{cSAR}(\mathrm{X})_{\text {CHD-X }}$} \\
\cline { 2 - 3 } & $R^{2}$ & $a$ \\
\hline $\mathrm{NO}_{2}$ & 0.974 & $1.160 \pm 0.051$ \\
$\mathrm{COOH}^{2}$ & 0.986 & $1.121 \pm 0.036$ \\
$\mathrm{COO}^{-}$ & 0.950 & $1.224 \pm 0.075$ \\
$\mathrm{OH}$ & 0.984 & $1.067 \pm 0.036$ \\
$\mathrm{O}^{-}$ & 0.861 & $1.471 \pm 0.158$ \\
$\mathrm{NH}_{2}$ & 0.983 & $1.178 \pm 0.041$ \\
\hline
\end{tabular}

$\mathrm{Y}$ and $\mathrm{X}$ substituents at the diene $\pi$-electron system in the position 3 than in the position 4. Two other characteristics, SESE and cSAR(Y), do not follow any reasonable linear correlations. All data are gathered in Table 1.

The advantage of using the cSAR approach is the ability to examine the substituent effect in terms of the electronic structure of the molecule. Thus, it is possible to compare the dependence of substituent properties on the functional group $\mathrm{Y}$ and the position of the substitution. The results of such comparison are shown in Table 2, the maximum and minimum values as well as the range of variation of cSAR parameters for $\mathrm{X}$ and $\mathrm{Y}$ fragments of the molecule. A graphic illustration of $\operatorname{cSAR}(\mathrm{X})$ variability for studied CHD systems is also shown in Fig. 2.

The differences between 1-4 and 1-3 interactions are clearly visible. Properties of functional groups $(\mathrm{Y})$ are almost four times stronger affected by substituents $(\mathrm{X})$ in the para position than in the meta one. Moreover, the mean ranges for $\operatorname{cSAR}(\mathrm{Y})$ and $\operatorname{cSAR}(\mathrm{X})$ are much greater for 1-4 than 1-3 interactions. This is due to the different components of the substituent effect in these cases. It is assumed that inductive and resonance effects are essentially equivalent for 1-4 interactions, whereas the latter significantly decreases for meta ones [10-12]. The obtained ranges of $\operatorname{cSAR}(\mathrm{Y})$ and $\operatorname{cSAR}(\mathrm{X})$ variation (Table 2) as well as their ratios document that communication between $\mathrm{Y}$ and $\mathrm{X}$ for 1-3 series is dramatically weaker than in the corresponding 1-4 systems (see also Table S12). The ability of the functional group to change properties of the substituent-a reverse substituent effect [34]—is confirmed by maximum and minimum $\operatorname{cSAR}(\mathrm{X})$ values for particular series.

As already mentioned, the CHD ring consists of paraffinic and olefinic parts. Therefore, by analogy with $\mathrm{BCO}$ derivatives [21, 25], cSAR $\left(\mathrm{CH}_{2}\right)$ in positions 5 and 6 (see Scheme 2) [denoted as cSAR(C5) and cSAR(C6)] in 4-X-CHD-Y derivatives should follow linear dependence on the inductive substituent constant $F$. Indeed, in both cases, $\operatorname{cSAR}(\mathrm{C} 5)$ and cSAR(C6), regressions are roughly acceptable; the same applies to their sum, marked as $\mathrm{cSAR}(\mathrm{C} 5+\mathrm{C} 6)$ and presented in Fig. 3a. Similarly, the changes in $\operatorname{cSAR}(\mathrm{CH})$ in positions 2 and 3 (Scheme 2), $\operatorname{cSAR}(\mathrm{C} 2+\mathrm{C} 3$ ), should follow the linear regression on the resonance substituent constants $R$ and indeed this works as shown in Fig. 3b. The obtained slopes of linear regressions (Table 3) reveal that the paraffin part of CHD is less affected by the substituent effect via the inductive effect than the olefin part affected by resonance effect. Statistical data are gathered in Table 3. Symptomatically, the correlations are worse for charged functional groups, $\mathrm{Y}=$ $\mathrm{COO}^{-}$and $\mathrm{O}^{-}$, than for the neutral $\mathrm{Y}$.

One of molecular parameters sometimes used to characterize the effect of the substituent is a valence angle at the ipso carbon, particularly well documented for monosubstituted benzene derivatives [38]. Its interpretation has been rationalized by electronegativity of the substituent $[39,40]$. We present an application of these ideas for 1-4 disubstituted CHD derivatives. Let us consider 1-nitro derivatives. Since the $\mathrm{NO}_{2}$ group is a strongly sigma and pi electron-attracting
Fig. 6 Relationships between $\varphi(1)$ (valence angle $\mathrm{C} 6, \mathrm{C} 1, \mathrm{C} 2$ ) and $\operatorname{cSAR}(\mathrm{X})$ and $\operatorname{cSAR}(\mathrm{Y})$ for 4 $\mathrm{X}-\mathrm{CHD}-\mathrm{NO}_{2}$ compounds

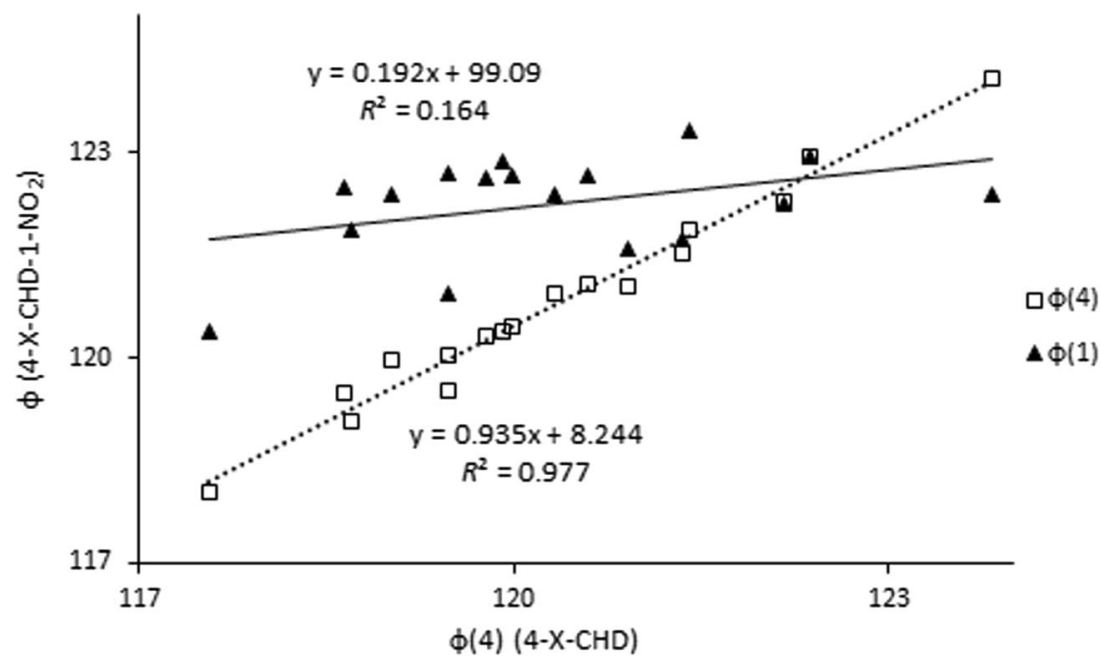


Fig. 7 Dependence of torsion angle of diene part (angle 1,2,3,4) on that of containing saturated one $(1,6,5,4)$ in $4-\mathrm{X}-\mathrm{CHD}-\mathrm{NO}_{2}$ systems; for $R \geq 0$ (filled diamonds) regression without point for $\mathrm{CONH}_{2}$

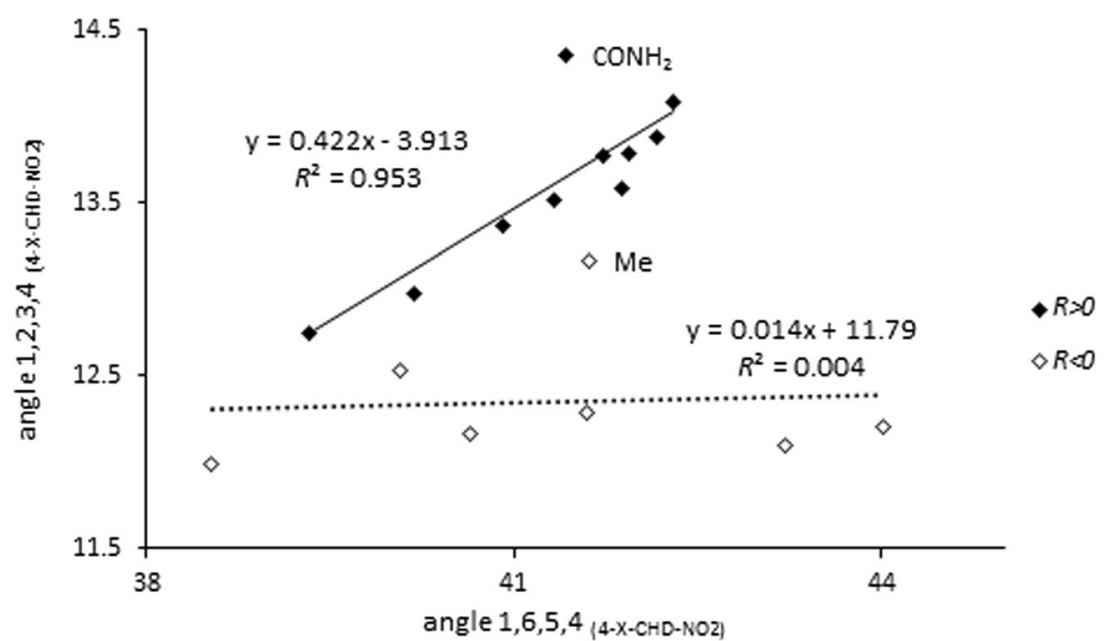

substituent, this may result in a behavior characteristic for strong interactions. Firstly, let us look at the valence angles $\varphi(1)$ and $\varphi(4)$ (see Scheme 2) at 4-X-CHD- $\mathrm{NO}_{2}$ series plotted against valence angles at the ipso carbon atom in monosubstituted CHD derivatives (Fig. 4). For the $\varphi(4)$ angle, the linear dependence is well defined, with $R^{2}=0.977$. This is easily understandable - a potential structural impact of X on a vicinity of the angle is in both cases nearly the same. The situation for $\varphi(1)$ is different; there are two kinds of interactions. The first one is geometrical in nature- the carbon skeleton is a nonplanar hexagon and changes in the angle at $\mathrm{C} 4$ influence the values of the angle at $\mathrm{C} 1$ - just due to the geometrical reasons. Additionally, a resonance effect acts via the olefinic part of the molecule. These may be reasons of the lack of linearity for $\varphi(1)$ in Fig. 4. Important to note that the slope for $\varphi(4)$ in $4-\mathrm{X}-\mathrm{CHD}-\mathrm{NO}_{2}$ systems plotted against valence angles at ipso carbon in monosubstituted CHD is smaller than 1 (slope $=0.935$ ). It suggests that $\mathrm{X} \cdots \mathrm{NO}_{2}$ interactions via the diene way decrease the charge at $\mathrm{X}$ and this results in a smaller variability of $\varphi(4)$ in disubstituted species. This hypothesis can be tested by the regression of $\operatorname{cSAR}(X)$ in 1-4 and monosubstituted CHD systems (Fig. 5 and Table 4). The obtained slope values for uncharged series are very similar; the mean value is 1.13. It indicates an enhancement of the charge flow resulting from the presence of the additional functional group Y. Moreover, positive values of slopes mean an increase $\operatorname{cSAR}(\mathrm{X})$ values, and this is charge at the substituent $\mathrm{X}$ decreases.

The valence angle $\varphi(1)$ (see Scheme 2) can be used to evaluate properties of the reaction center $\mathrm{Y}$. The mutual interactions between the functional group $\mathrm{Y}$ and substituents $\mathrm{X}$ are visualized by dependence of $\varphi(1)$ on both $\operatorname{cSAR}(\mathrm{X})$ and cSAR $(\mathrm{Y})$ in 1-4 disubstituted $\mathrm{X}-\mathrm{CHD}-\mathrm{Y}$, presented in Fig. 6. The obtained linear regressions have good determination coefficients $\left(R^{2}>0.923\right)$ indicating good interrelationships between $\varphi(1)$ and charges at $\mathrm{C} 1$ and $\mathrm{C} 4$ active regions. As abovementioned, the ipso angle $\varphi$ is related to group electronegativity $[39,40]$. Therefore, it allows to assume that interactions between $\mathrm{X}$ and $\mathrm{Y}$ change electronegativities of both interacting $\mathrm{X}$ and $\mathrm{Y}$ [41].

One more characteristic of 1-4 disubstituted CHD nitro derivatives is impact of the substituent on the torsion angles (C1,C6,C5,C4 and C1,C2,C3,C4, below denoted as 1,6,5,4
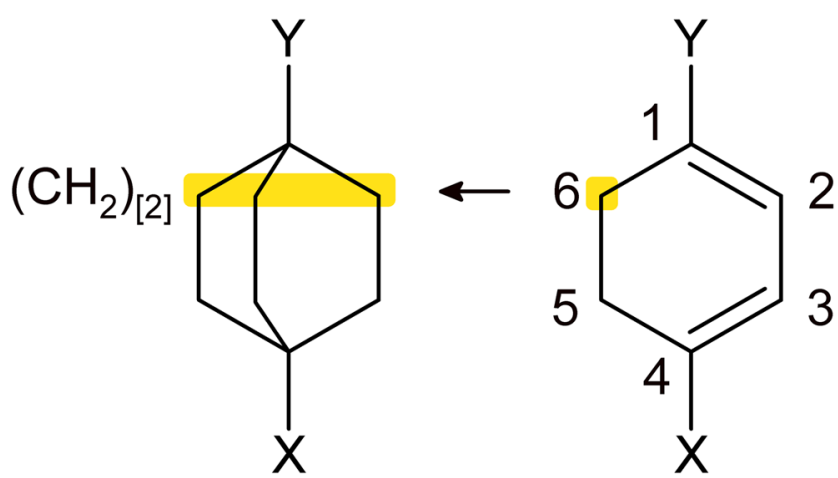

Scheme 3 Comparison of the $\operatorname{cSAR}\left(\mathrm{CH}_{2}\right)_{[2]}$ for 1,4-disubstituted bicyclo[2.2.2] octane (BCO) and cSAR(C6) for 1-4 CHD-Y series
Table 5 Values of the slope, $a$, and determination coefficient, $R^{2}$, for the obtained linear relations between $\operatorname{cSAR}(\mathrm{C} 6)$ in $\mathrm{CHD}$ and $\mathrm{cSAR}\left(\mathrm{CH}_{2}\right)_{[2]}$ in $\mathrm{BCO}$ disubstituted systems

\begin{tabular}{lll}
\hline $\mathrm{Y}$ & \multicolumn{2}{c}{$\mathrm{cSAR}(\mathrm{C} 6)_{\mathrm{CHD}} \operatorname{vscSAR}\left(\mathrm{CH}_{2}\right)_{[2]} \mathrm{BCO}$} \\
\cline { 2 - 3 } & $R^{2}$ & $a$ \\
\hline $\mathrm{NO}_{2}$ & 0.841 & $1.677 \pm 0.188$ \\
$\mathrm{COOH}$ & 0.845 & $1.616 \pm 0.185$ \\
$\mathrm{COO}^{-}$ & 0.684 & $2.458 \pm 0.447$ \\
$\mathrm{OH}$ & 0.858 & $1.837 \pm 0.193$ \\
$\mathrm{O}^{-}$ & 0.825 & $2.299 \pm 0.274$ \\
$\mathrm{NH}_{2}$ & 0.896 & $1.604 \pm 0.147$ \\
\hline
\end{tabular}


Fig. 8 Dependences of cSAR(C6) in 1-4 CHD-Y on cSAR $\left(\mathrm{CH}_{2}\right)_{[2]}$ in 1-4 BCO-Y substituted derivatives; $\mathrm{Y}=\mathrm{NO}_{2}$, $\mathrm{COOH}, \mathrm{COO}^{-}, \mathrm{OH}, \mathrm{O}^{-}$, and $\mathrm{NH}_{2}$

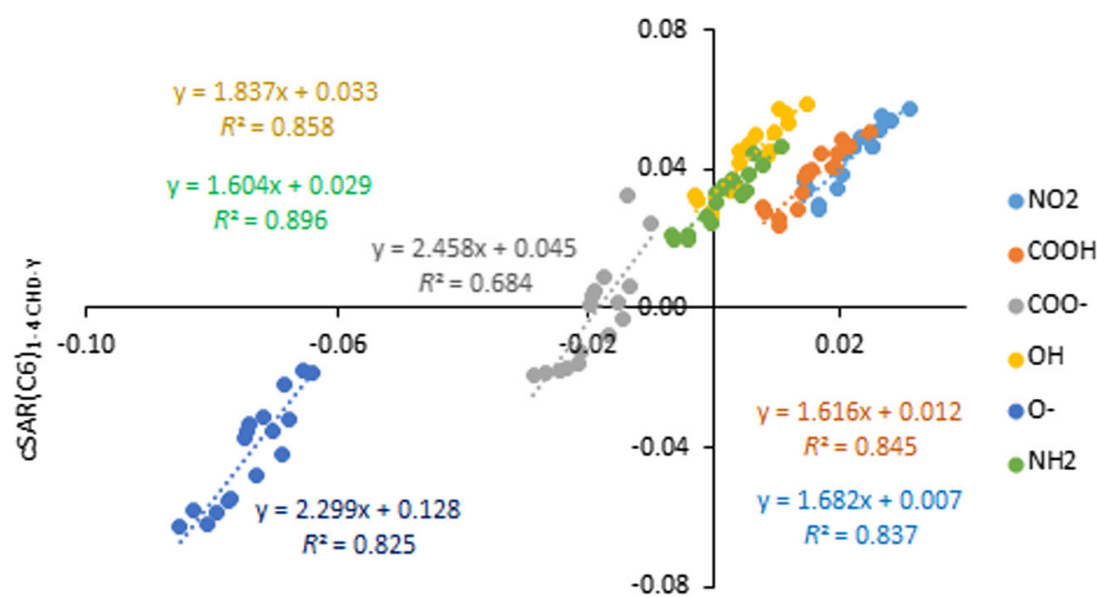

$\operatorname{cSAR}\left(\mathrm{CH}_{2}\right)_{[2]} 1-4 \mathrm{BCO}-\mathrm{r}$ and 1,2,3,4, numbering of atoms, see Scheme 2). This may be a reason of interesting features shown in Fig. 7, where relations between the absolute values of the torsion angle are presented. Firstly, the variability range of the angle $1,2,3,4$ is smaller than for the angle $1,6,5,4$; it reads as 2.5 vs $5.5^{\circ}$. This is understandable - the olefinic part of CHD is much stiffer than the paraffinic one. Secondly, for electron-donating substituents (with $R<0.0$ ), the $1,2,3,4$ torsion angle is nearly constant whereas for electron-accepting substituents $(R \geq$ $0.0)$, both angles are mutually related $\left(R^{2}=0.953\right.$ for data without $\mathrm{X}=\mathrm{CONH}_{2}$ ) with a positive slope. It means that the delocalization in the diene part (its planarity) strongly depends on the nature of a substituent which is counteracting to the electron-accepting character of $\mathrm{Y}=\mathrm{NO}_{2}$. From the above results, it may be stated that the planarity of the diene part of CHD is favorable for charge transfer along the diene part. Opposite to this, a weaker charge transfer is associated with a substantial changes in 1,2,3,4 torsion angle. It has to be added that in the case of other functional groups, e.g., $\mathrm{Y}=$ $\mathrm{NH}_{2}$, no such relationships are observed.
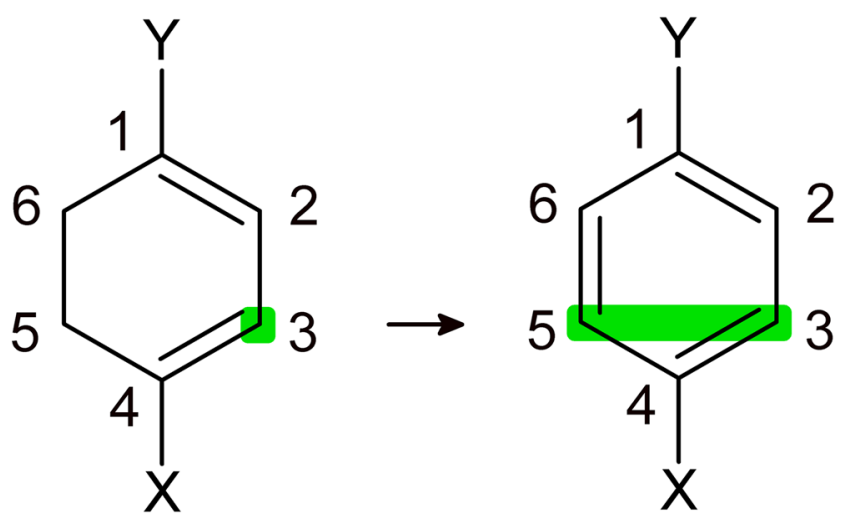

Scheme 4 A comparison of the $\operatorname{cSAR}(\mathrm{C} 3)$ for 1-4 CHD series with cSAR $(\mathrm{C} 3, \mathrm{C} 5)$ [average value] for para substituted BEN derivatives

\section{Comparison of the substituent effect in 1-4 disubstituted CHD and BCO systems}

The saturated part of CHD differs from that in $\mathrm{BCO}$. In $\mathrm{BCO}$, there exists an additional force acting from the ring constraints to change $\mathrm{sp}^{3}$ carbon atoms $\left(\left(\mathrm{CH}_{2}\right)_{[2]}\right.$, Scheme 3$)$ in BCO in a direction to increase the planarity of this part. This may be observed by a comparison of torsion angles in the aliphatic part of CHD and in BCO (Scheme 3). In CHD, for $\mathrm{Y}=\mathrm{NO}_{2}$ and $\mathrm{NH}_{2}$ systems, the average absolute values of the $1,6,5,4$ torsion angle are 41 and $44^{\circ}$, respectively, whereas for BCO series, the corresponding parts are significantly more planar (angles are ca. $10^{\circ}$ ).

The abovementioned differences between the substituent effect observed in CHD and BCO can also be documented by a comparison of the impact of the functional group $\mathrm{Y}$ in $\mathrm{CHD}$ and $\mathrm{BCO}$ on $\mathrm{cSAR}\left(\mathrm{CH}_{2}\right)$ values in vicinal positions. Statistical data for these dependences are presented in Table 5 and the appropriate regressions are shown in Fig. 8. For uncharged functional $\mathrm{Y}$, the mean slope value is 1.69 . It means that this carbon atom in CHD systems is significantly

Table 6 Values of the slope, $a$, and determination coefficient, $R^{2}$, for the obtained linear relations between $\operatorname{cSAR}(\mathrm{C} 3)$ in $\mathrm{CHD}$ and $\mathrm{cSAR}(\mathrm{C} 3, \mathrm{C} 5)$ in BEN for 1-4 substituted derivatives

\begin{tabular}{lll}
\hline $\mathrm{Y}$ & \multicolumn{2}{c}{$\mathrm{cSAR}(\mathrm{C} 3)_{1-4}$ CHD-Y vs cSAR(C3,C5) para BEN-Y } \\
\cline { 2 - 3 } & $R^{2}$ & $a$ \\
\hline $\mathrm{NO}_{2}$ & 0.962 & $1.855 \pm 0.095$ \\
$\mathrm{COOH}^{2}$ & 0.967 & $1.762 \pm 0.088$ \\
$\mathrm{COO}^{-}$ & 0.982 & $1.656 \pm 0.060$ \\
$\mathrm{OH}$ & 0.959 & $1.884 \pm 0.100$ \\
$\mathrm{O}^{-}$ & 0.958 & $1.420 \pm 0.076$ \\
$\mathrm{NH}_{2}$ & 0.955 & $1.774 \pm 0.102$ \\
\hline
\end{tabular}


Fig. 9 Dependences of cSAR(C3) in 1-4 CHD-Y and in para $\mathrm{BEN}-\mathrm{Y}$ disubstituted derivatives, where $\mathrm{Y}: \mathrm{NO}_{2}, \mathrm{COOH}$, $\mathrm{COO}^{-}, \mathrm{OH}, \mathrm{O}^{-}$, and $\mathrm{NH}_{2}$

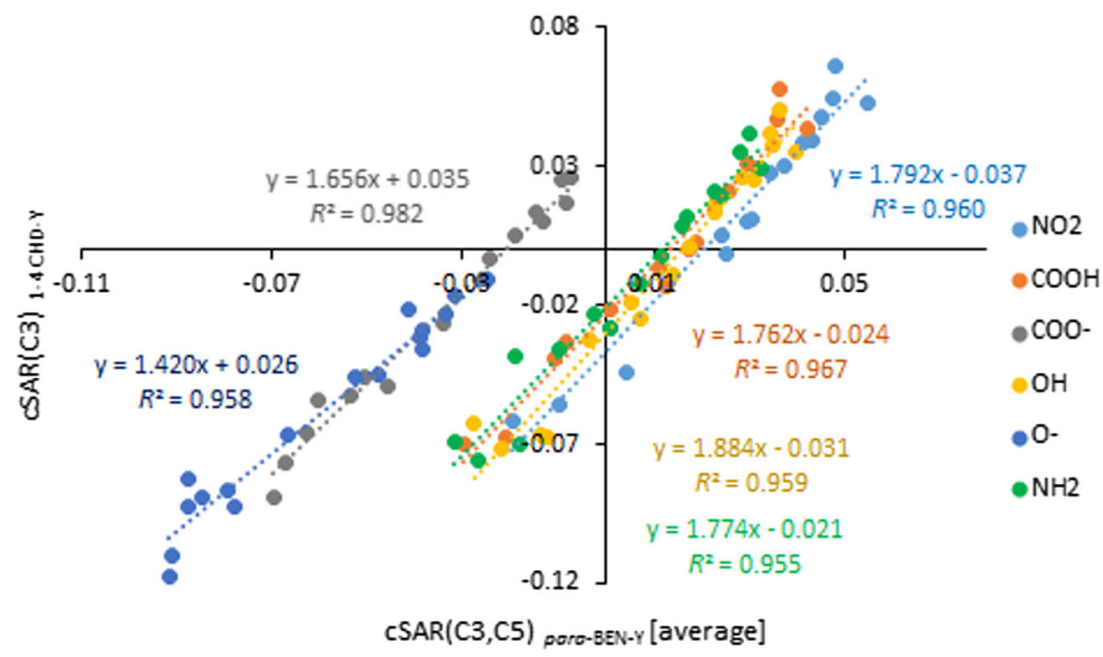

more affected by the substituent effect than the one in $\mathrm{BCO}$ series.

\section{Comparisons of the substituent effect for 1-4 (1-3) CHD and para (meta) benzene derivatives}

Due to a complex nature of presented comparisons, they are discussed in several subsections.

\section{Dependences between $\mathrm{CSAR}(\mathrm{C} 3)(\mathrm{CHD})$ and $\mathrm{CSAR}(\mathrm{C} 3, \mathrm{C} 5)(\mathrm{BEN})$}

The position 3 in CHD is analogous to the meta one in benzene and it seems to be reasonable to compare cSAR(C3) in 1-4 CHD systems with a mean value of cSAR $(\mathrm{CH})$ in para benzene derivatives, denoted as cSAR(C3,C5) (Scheme 4).

As shown in Table 6 and Fig. 9, the obtained regressions have high determination coefficients, $R^{2}>0.955$ and the slopes are greater than 1.762 for uncharged substituents (the mean values are 1.819) and equal to 1.420 and 1.656 for $\mathrm{Y}=$ $\mathrm{O}^{-}$and $\mathrm{COO}^{-}$, respectively. This result shows a much stronger substituent effect on $\mathrm{CH}$ units in the position 3 of CHD than in benzene. Furthermore, an analogical comparison of CHD with BCO series (Table 5) indicates a similar enhancement of the SE.

\section{Comparison SESE parameters in CHD and BEN series}

SESE - an energetic characteristic of the substituent effect-takes into account all intramolecular interactions. Hence, a comparison of SESE values for 1-3 and 1-4 substituted CHD and benzene is very informative. As we see in Table 7 and Fig. S1, for 1-4 interactions, all determination coefficients are very high $\left(R^{2}>0.978\right)$ and slightly worse for 1-3 interactions, except of the data for
3-X-R-OH systems. Important to notice that the slopes for 1-4 derivatives are as an average 1.333 and 1.193 for neutral and charged Y, respectively. Thus, one may say that the "mixed" transmitting moiety - CHD - is more effective in charge transfer than the aromatic one (BEN), in line with earlier reports [31]. In contrast, for 1-3 interactions, the benzene moiety is more effective than CHD except for $\mathrm{Y}=\mathrm{NH}_{2}$, the slopes are between 0.556 and 0.846 .

\section{Comparison $\mathrm{CSAR}(\mathrm{X})$ values in $\mathrm{CHD}$ and BEN disubstituted derivatives}

A similar picture, to that presented above, is observed by looking at $\operatorname{cSAR}(\mathrm{X})$ determined in 1-3 and 1-4 disubstituted $\mathrm{CHD}$ and BEN derivatives. The obtained data are gathered in Table 8 and shown in Fig. S2. All regressions have very high determination coefficients $\left(R^{2}>0.971\right)$. Again, 1-4 interactions are more effective in CHD than in BEN derivatives (by

Table 7 Values of the slope, $a$, and a determination coefficient, $R^{2}$, for the obtained correlations between SESE values obtained for CHD and BEN disubstituted derivatives

\begin{tabular}{|c|c|c|c|c|}
\hline \multirow[t]{3}{*}{ Y } & \multicolumn{4}{|c|}{$\mathrm{SESE}_{\mathrm{CHD}}$ vs $\mathrm{SESE}_{\mathrm{BEN}}$} \\
\hline & \multicolumn{2}{|c|}{ 1-4 interaction } & \multicolumn{2}{|c|}{ 1-3 interaction } \\
\hline & $R^{2}$ & $a$ & $R^{2}$ & $a$ \\
\hline $\mathrm{NO}_{2}$ & 0.980 & $1.294 \pm 0.048$ & 0.941 & $0.826 \pm 0.054$ \\
\hline $\mathrm{COOH}$ & 0.984 & $1.401 \pm 0.047$ & 0.784 & $0.771 \pm 0.108$ \\
\hline $\mathrm{COO}^{-}$ & 0.978 & $1.157 \pm 0.046$ & 0.689 & $0.556 \pm 0.100$ \\
\hline $\mathrm{OH}$ & 0.969 & $1.338 \pm 0.062$ & 0.050 & $0.251 \pm 0.282$ \\
\hline $\mathrm{O}^{-}$ & 0.991 & $1.231 \pm 0.030$ & 0.957 & $0.846 \pm 0.046$ \\
\hline $\mathrm{NH}_{2}$ & 0.992 & $1.299 \pm 0.032$ & 0.857 & $1.673 \pm 0.183$ \\
\hline
\end{tabular}


Table 8 Values of the slope, $a$, and determination coefficient, $R^{2}$, for the obtained correlations between $\operatorname{cSAR}(\mathrm{X})$ in $\mathrm{CHD}$ and $\mathrm{BEN}$ disubstituted derivatives

\begin{tabular}{|c|c|c|c|c|}
\hline \multirow[t]{3}{*}{ Y } & \multicolumn{4}{|c|}{$\operatorname{cSAR}(\mathrm{X})_{\mathrm{CHD}}$ vs cSAR $(\mathrm{X})_{\mathrm{BEN}}$} \\
\hline & \multicolumn{2}{|c|}{ 1-4 interaction } & \multicolumn{2}{|c|}{ 1-3 interaction } \\
\hline & $R^{2}$ & $a$ & $R^{2}$ & $a$ \\
\hline $\mathrm{NO}_{2}$ & 0.993 & $1.181 \pm 0.027$ & 0.981 & $0.889 \pm 0.032$ \\
\hline $\mathrm{COOH}$ & 0.992 & $1.152 \pm 0.029$ & 0.982 & $0.883 \pm 0.032$ \\
\hline $\mathrm{COO}^{-}$ & 0.971 & $1.259 \pm 0.058$ & 0.997 & $0.945 \pm 0.014$ \\
\hline $\mathrm{OH}$ & 0.984 & $1.156 \pm 0.039$ & 0.977 & $0.872 \pm 0.035$ \\
\hline $\mathrm{O}^{-}$ & 0.989 & $1.217 \pm 0.033$ & 0.984 & $0.980 \pm 0.032$ \\
\hline $\mathrm{NH}_{2}$ & 0.982 & $1.181 \pm 0.042$ & 0.975 & $0.903 \pm 0.039$ \\
\hline
\end{tabular}

about 1.2), whereas in the case of 1-3 interactions, the opposite relation occurs (the slope is $\sim 0.9$ ).

\section{Comparison CFI values in CHD and BEN disubstituted derivatives}

The influence of the substituent effect on the electronic structure of the system can be characterized by a charge flow index (CFI), defined as:

$\mathrm{CFI}=\operatorname{cSAR}(\mathrm{Y})-\mathrm{cSAR}(\mathrm{X})$

Its advantage is the ability to simultaneously compare the electronic properties of a fixed Y group and the substituent X. For uncharged systems, negative values of the CFI show stronger electron-accepting properties of $\mathrm{Y}$ than $\mathrm{X}$ whereas positive ones indicate the opposite electron abilities of $\mathrm{Y}$ and $\mathrm{X}$.

Results of the performed analysis reveal that for 1-4 interactions, greater charge transfer takes place in CHD than in BEN series (Table 9 and Fig. 10). In turn, the opposite is in

Table 9 Values of the slope, $a$, and determination coefficient, $R^{2}$, for the obtained correlations between CFI in CHD and BEN disubstituted derivatives

\begin{tabular}{|c|c|c|c|c|}
\hline \multirow[t]{3}{*}{ Y } & \multicolumn{4}{|c|}{$\mathrm{CFI}_{\mathrm{CHD}}$ vs $\mathrm{CFI}_{\mathrm{BEN}}$} \\
\hline & \multicolumn{2}{|c|}{ 1-4 interaction } & \multicolumn{2}{|c|}{ 1-3 interaction } \\
\hline & $R^{2}$ & $a$ & $R^{2}$ & $a$ \\
\hline $\mathrm{NO}_{2}$ & 0.993 & $1.236 \pm 0.027$ & 0.980 & $0.896 \pm 0.033$ \\
\hline $\mathrm{COOH}$ & 0.992 & $1.208 \pm 0.030$ & 0.980 & $0.882 \pm 0.033$ \\
\hline $\mathrm{COO}^{-}$ & 0.966 & $1.321 \pm 0.066$ & 0.996 & $0.933 \pm 0.016$ \\
\hline $\mathrm{OH}$ & 0.984 & $1.176 \pm 0.039$ & 0.975 & $0.845 \pm 0.035$ \\
\hline $\mathrm{O}^{-}$ & 0.987 & $1.201 \pm 0.036$ & 0.979 & $1.007 \pm 0.038$ \\
\hline $\mathrm{NH}_{2}$ & 0.984 & $1.232 \pm 0.042$ & 0.975 & $0.900 \pm 0.039$ \\
\hline
\end{tabular}

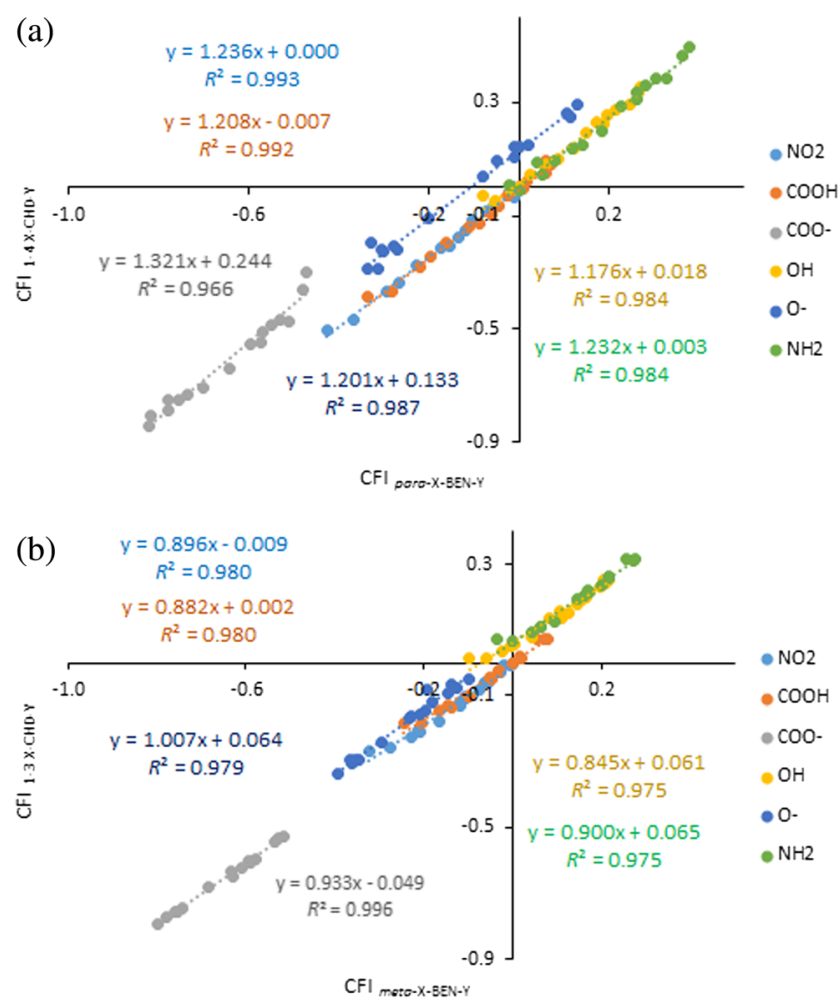

Fig. 10 Dependences of CFI values in CHD on those in BEN systems for 1-4 (a) and 1-3 (b) interactions; $\mathrm{Y}=\mathrm{NO}_{2}, \mathrm{COOH}, \mathrm{COO}^{-}, \mathrm{OH}, \mathrm{O}^{-}$, and $\mathrm{NH}_{2}$

the case of 1-3 interactions, with exception $\mathrm{Y}=\mathrm{O}^{-}$. For meta substituted systems, significantly stronger substituent effects are observed in aromatic systems than in CHD derivatives (see Table S14 and Fig. S3). In addition, it should be stressed that all obtained $\mathrm{CFI}_{\mathrm{CHD}}$ vs $\mathrm{CFI}_{\mathrm{BEN}}$ linear regressions (Table 9) characterize determination coefficients greater than 0.975 , in the case of $\mathrm{CFI}_{1-3}$ vs $\mathrm{CFI}_{1-4}$ relations, they are a bit worse $\left(R^{2}\right.$ $>0.918$, Table S14).

\section{Conclusions}

To summarize, we have investigated the substituent effects in disubstituted cyclohexa-1,3-diene (CHD) derivatives in comparison to two reference systems, namely the corresponding bicyclo[2.2.2] octane (BCO) and benzene (BEN) derivatives. The studied series differ in the transmitting moiety, which is fully saturated in $\mathrm{BCO}$, fully aromatic in BEN, and mixed (saturated and diene type) in CHD derivatives. Thus, for this purpose, quantum chemistry models of the substituent effect (cSAR and SESE), traditional Hammett's substituent constants $(\sigma)$, and their inductive $(F)$ and resonance $(R)$ components were used, whereas $\pi$-electron delocalization of the transmitting moiety was described by the HOMA index. The obtained results allow to formulate the following conclusions: 
(i) The substituent effect descriptors are mutually well correlated for all 1-4 disubstituted CHD derivatives and clearly worse for 1-3 CHD ones. This applies to interrelations between substituent effect characteristics and Hammett-type relations. In the first case, the worst $R^{2}$ for 1-4 derivatives is 0.800 , whereas for $1-3$ ones is 0.680 , excluding hydroxy-CHD derivatives. The second case is similar. Electron-accepting properties of the substituent in position 3 of CHD-OH $\left(\sigma_{\mathrm{m}}=0.12\right.$ for benzene series) results in a lack of correlation for 1-3 CHD-OH derivatives; the same is observed for meta-X-phenols.

(ii) Very good correlations between HOMA and SESE are found for 1-4 CHD systems with opposite character of the substituent $\mathrm{X}$ and the fixed group $\mathrm{Y}$; an increase of substituent stabilization effect ( $\mathrm{SESE}>0$ ) is associated with an increase of the $\pi$-electron delocalization.

(iii) The obtained $\operatorname{cSAR}(\mathrm{Y})$ values for $\mathrm{CHD}$ series reveal that the functional groups properties are almost four times more strongly affected by the substituents in the para position than in the meta one. Thus, different inductive and resonance components of the substituent effect are encountered in 1-4 and 1-3 intramolecular interactions. Statistical analysis of $\operatorname{cSAR}(\mathrm{Y})$ and $\operatorname{cSAR}(\mathrm{X})$ data for the CHD series shows dramatically weaker communications between $\mathrm{Y}$ and $\mathrm{X}$ for 1-3 than in the case of 1-4 accompanied with the reverse SE.

(iv) $\mathrm{A}$ comparison of the substituent effect on the vicinal $\mathrm{CH}_{2}$ groups in the saturated part of CHD and in BCO indicates its dramatically greater impact in the $\mathrm{CHD}$ case $(\sim 1.6$ times for uncharged $\mathrm{Y}$ and $\sim 2.4$ for $\mathrm{Y}=$ $\mathrm{COO}^{-}$or $\mathrm{O}^{-}$). This is associated with an additional substituent effect in CHD through the diene path.

(v) The substituent effect on the vicinal $\mathrm{CH}$ groups related to $\mathrm{X}$ in the diene part of CHD is dramatically greater than in benzene (by $\sim 1.7$ ), indicating greater mobility of the $\pi$ electron structure in the 1-4 substituted CHD series as compared to the case of the corresponding benzene derivatives. The use of SESE and CFI parameters for this purpose also confirms the above-formulated conclusion. In contrast, for 1-3 interactions, more effective communications between $\mathrm{Y}$ and $\mathrm{X}$ by benzene moiety are found.

(vi) For 4-X-CHD- $\mathrm{NO}_{2}$ derivatives, the ipso valence angle at the carbon atom $\left(\mathrm{C} 1-\mathrm{NO}_{2}\right)$ correlates well with that of $\operatorname{cSAR}(\mathrm{X})$ and $\operatorname{cSAR}\left(\mathrm{NO}_{2}\right)$, respectively, indicating that the charge transfer from the substituent through the diene part to the nitro group significantly changes the electronegativity of the latter.

Summarizing, a detailed comparison of the substituent effect determined for alicyclic and aromatic systems with the one in CHD derivatives well documents the interplay between inductive and resonance contributions of the substituent effect.
Funding information The authors acknowledge the Interdisciplinary Center for Mathematical and Computational Modeling (Warsaw, Poland) and Wrocław Centre for Networking and Supercomputing (http://wcss.pl; grant no. 311) for providing computer time and facilities. K.S.V. thanks the Ministry of Education and Science of the Russian Federation (the project number 4.1657.2017/4.6). H.S. and T. M.K. thank the National Science Centre and Ministry of Science and Higher Education of Poland for supporting this work under the grant no. UMO-2013/11/B/ST4/00531.

\section{Compliance with ethical standards}

Conflict of interest The authors declare that they have no conflict of interest.

Open Access This article is distributed under the terms of the Creative Commons Attribution 4.0 International License (http:// creativecommons.org/licenses/by/4.0/), which permits unrestricted use, distribution, and reproduction in any medium, provided you give appropriate credit to the original author(s) and the source, provide a link to the Creative Commons license, and indicate if changes were made.

\section{References}

1. Tyśkiewicz K, Dębczak A, Gieysztor R, Szymczak T, Rój E (2018). J Sep Sci 41:336-350

2. Feng MT, Wang T, Liu AH, Li J, Yao LG, Wang B, Guo YW, Mao SC (2018). Phytochemistry 146:25-35

3. Martucciello S, Paolella G, Muzashvili T, Skhirtladze A, Pizza C, Caputo I, Piacente S (2018). Chem Biol Interact 279:43-50

4. Westlund P, Isazadeh S, Yargeau V (2018). J Hazard Mater 342: 492-498

5. Srivastava S, Shree P, Pandey H, Tripathi YB (2018). Biomed Pharmacother 97:330-338

6. Krygowski TM, Ejsmont K, Stepien MK, Poater J, Sola M (2004). J Org Chem 69:6634-6640

7. Norman ROC, Taylor R (1964) Electrophilic substitution in benzenoid compounds. Elsevier Publ Comp Amsterdam

8. Smith MB, March J (2001) March's advanced organic chemistry. New York, Wiley $675 \mathrm{ff}$

9. Hammett LP (1940) Physical organic chemistry. McGraw - Hill, New York $196 \mathrm{ff}$

10. Taft RW, Lewis IC (1958). J Am Chem Soc 80:2436-2443

11. Taft RW, Lewis IC (1959). J Am Chem Soc 81:5343-5361

12. Exner O (1972) In: Chapman NB, Shorter J (eds) Advances in linear free energy relationships, Chapter 1. Plenum Press, London, $\mathrm{p} 1$

13. McDaniel DH, Brown HC (1958). J Org Chem 23:420-427

14. Yamdagni R, McMahon TB, Kebarle P (1974). J Am Chem Soc 96: 4035-4037

15. Biggs AI, Robinson RA (1961) J Chem Soc 388-393

16. Krygowski TM, Fawcett WR (1977). J Chem Soc Perk Trans 2: 2033-2037

17. Sadlej-Sosnowska N (2007). Chem Phys Lett 447:192-196

18. Krygowski TM, Sadlej-Sosnowska N (2011). Struct Chem 22:17-22

19. Roberts JD, Moreland WT (1953). J Am Chem Soc 75:2167-2173

20. Exner O, Bohm S (2003). Chem Eur J 9:4718-4723

21. Szatyłowicz H, Siodla T, Krygowski TM (2017) ACS. Omega 2: 1746-1749

22. Topsom DR (1981). J Am Chem Soc 103:39-44

23. Topsom RD (1983). Acc Chem Res 16:292-298

24. Exner O, Böhm S (2006). Curr Org Chem 10:763-778 
25. Szatylowicz H, Jezuita A, Siodla T, Varaksin KS, Domanski MA, Ejsmont K, Krygowski TM (2017). ACS Omega 2:7163-7171

26. Szatylowicz H, Siodla T, Stasyuk OA, Krygowski TM (2016). Phys Chem Chem Phys 18:11711-11721

27. Shahamirian M, Szatylowicz H, Krygowski TM (2017). Struct Chem 28:1563-1572

28. Varaksin KS, Szatylowicz H, Krygowski TM (2017). J Mol Struct 1137:581-588

29. Szatylowicz H, Jezuita A, Ejsmont K, Krygowski TM (2017). Struct Chem 28:1125-1132

30. Frisch MJ, Trucks GW, Schlegel HB, Scuseria GE, Robb MA, Cheeseman JR, Scalmani G, Barone V, Mennucci B, Petersson GA, Nakatsuji H, Caricato M, Li X, Hratchian HP, Izmaylov AF, Bloino J, Zheng G, Sonnenberg JL, Hada M, Ehara M, Toyota K, Fukuda R, Hasegawa J, Ishida M, Nakajima T, Honda Y, Kitao O, Nakai H, Vreven T, Montgomery Jr JA, Peralta JE, Ogliaro F, Bearpark M, Heyd JJ, Brothers E, Kudin KN, Staroverov VN, Kobayashi R, Normand J, Raghavachari K, Rendell A, Burant JC, Iyengar SS, Tomasi J, Cossi M, Rega N, Millam JM, Klene M, Knox JE, Cross JB, Bakken V, Adamo C, Jaramillo J, Gomperts R, Stratmann RE, Yazyev O, Austin AJ, Cammi R, Pomelli C, Ochterski JW, Martin RL, Morokuma K, Zakrzewski VG, Voth GA, Salvador P, Dannenberg JJ, Dapprich S, Daniels AD, Farkas
Ö, Foresman JB, Ortiz JV, Cioslowski J, Fox DJ (2009) Gaussian 09, Revision D.01. Gaussian, Inc., Wallingford CT

31. Szatylowicz H, Siodla T, Krygowski TM (2017) Olefinic vs aromatic way of substituent effects: the case of 3- and 4-substituted cyclohexa-1,3-dienamine derivatives. J Phys Org Chem 30:e3694

32. George P, Trachtman M, Bock CW, Brett AM (1976). J Chem Soc Perk Trans 2:1222-1227

33. Hirshfeld FL (1977). Theor Chim Acta 44:129-138

34. Stasyuk OA, Szatylowicz H, Fonseca Guerra C, Krygowski TM (2015). Struct Chem 26:905-913

35. Krygowski TM (1993). J Chem Inf Comput Sci 33:70-78

36. Hansch C, Leo A, Taft RW (1991). Chem Rev 91:165-195

37. Siodla T, Szatylowicz H, Varaksin KS, Krygowski TM (2016). RSC Adv 6:96527-96530

38. Domenicano A (1992) In: Domenicano A, Hargittai I (Edts) Accurate molecular structures, their determination and importance, Chapter 18. International Union of Crystallography, Oxford University Press, pp 437-467

39. Domenicano A, Murray-Rust P (1979). Tetrahedron Lett (24): 2283-2286

40. Campanelli AR, Domenicano A, Ramondo F (2003). J Phys Chem A 107:6429-6440

41. Krygowski TM, Szatyłowicz H (2006). J Phys Chem A 110:72327236 